Sheffield

Hallam

University

Centre for

Regional Economic and Social Research

\title{
Universal Credit in Rotherham: A transition to full service
}

\author{
Christina Beatty \\ Larissa Povey
}




\section{Universal Credit in Rotherham: A transition to full service}

Authors:

Christina Beatty

Larissa Povey

July 2018 


\section{Contents}

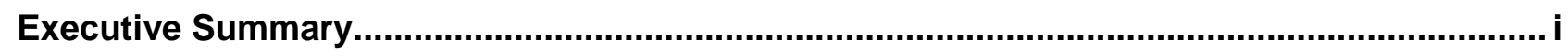

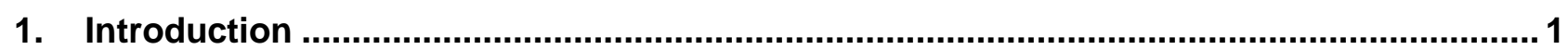

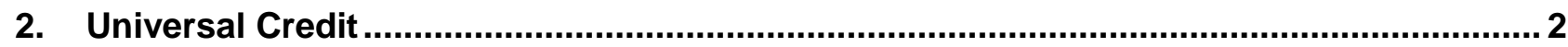

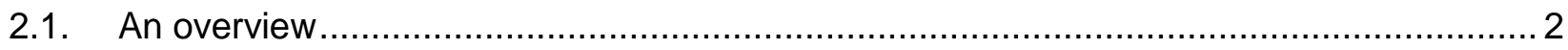

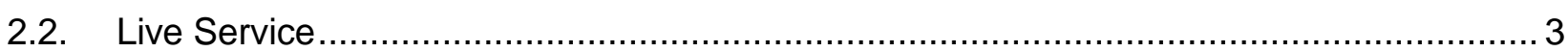

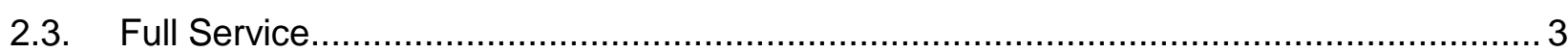

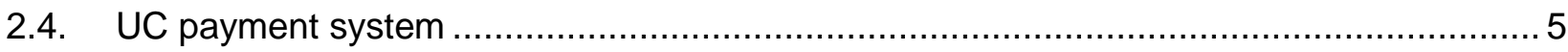

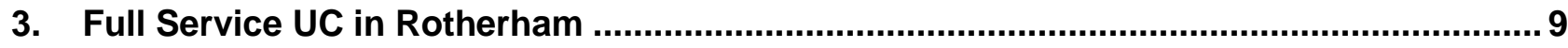

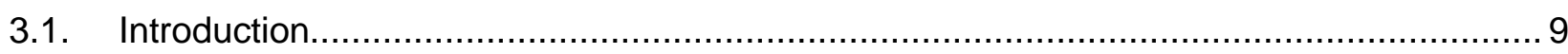

3.2. Live Service UC claims in Rotherham......................................................................

3.3. Legacy benefit claimants in Rotherham .................................................................. 10

3.4. Rotherham constituency data for Universal Credit roll-out .......................................... 11

4. Roll-out of Full Service UC.........................................................................................

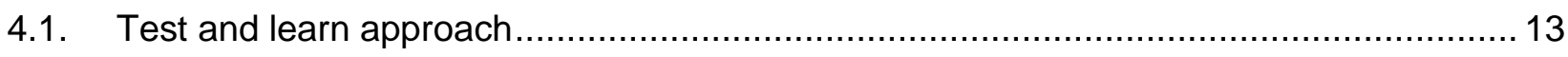

4.2. DWP survey of Full Service claimants .................................................................... 13

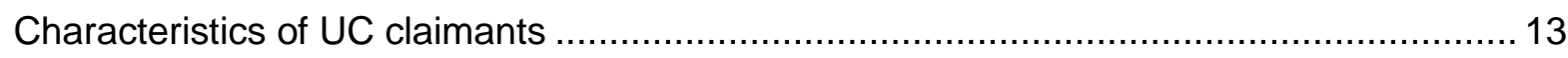

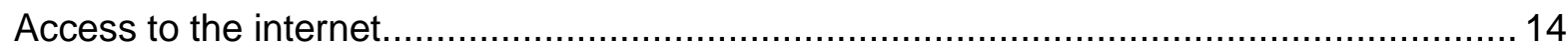

Difficulties in making an on-line claim:...................................................................... 14

Using the UC Service Centre ........................................................................................ 14

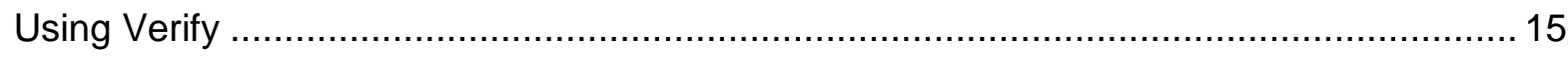

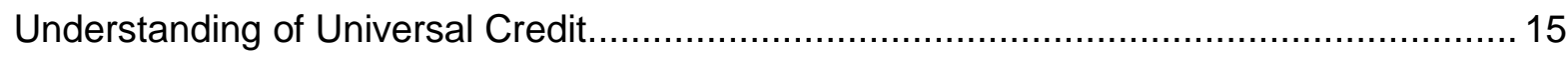

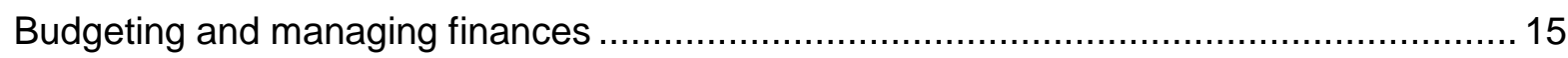

Housing and managing housing payments....................................................................... 16

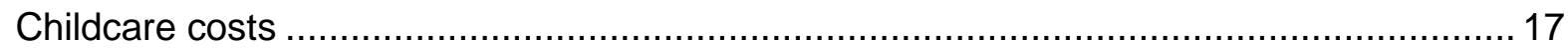


4.3. Summary of findings and additional support needed

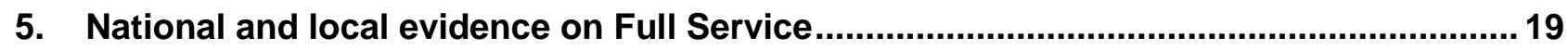

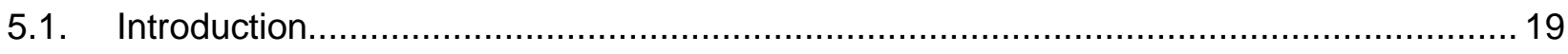

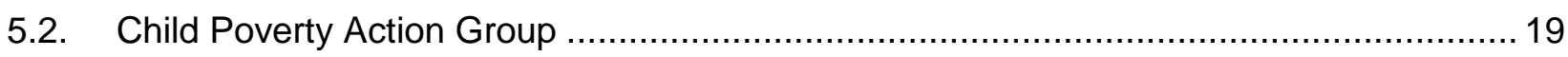

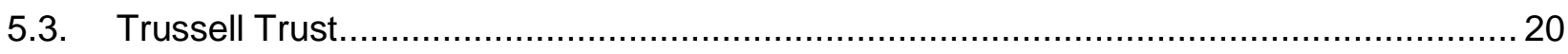

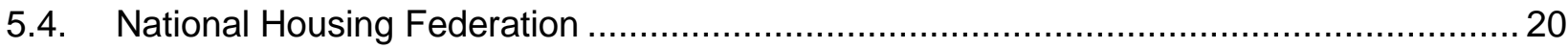

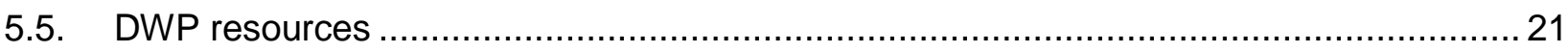

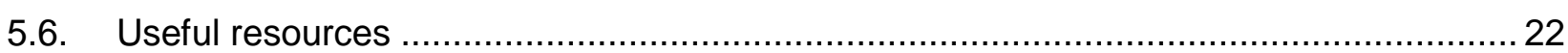

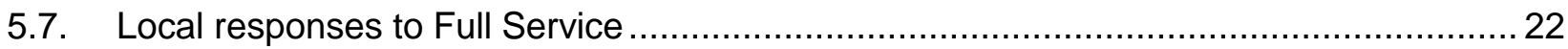

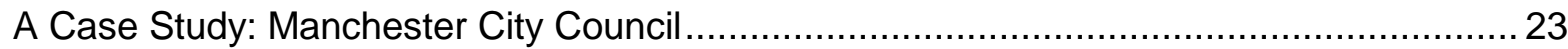

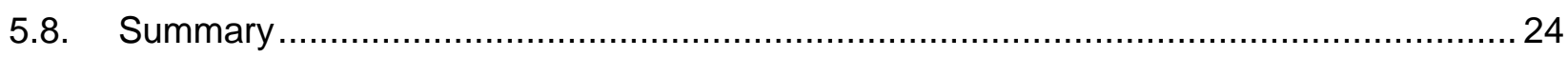




\section{Executive Summary}

- Universal Credit (UC) is a key element of the government's Welfare Reform agenda. It is available to working age people on low incomes - including those who are in work or out of work. UC replaces six income-based benefits: Income-based Jobseeker's Allowance, income-based Employment and Support Allowance, Income Support, Working Tax Credit, Child Tax Credit and Housing Benefit.

- UC has gradually been introduced across Jobcentre Plus areas since 2013. Initially, this was for limited types of claimants through Live Service UC. Since May 2016, Full Service UC has gradually been rolled-out across the country. This is a fully digitised service where claimants make and manage their claim on-line. This process should be complete by December 2018.

- In the first instance, Full Service UC is available to new working age claimants requiring income-based financial support, existing claimants who have a change of circumstances or those who opt-in to the system. For now, claimants with three or more children will continue to make new claims to legacy benefits. Tenants who live in supported "exempt" accommodation can make a UC claim but their housing costs will continue to be administered via Housing Benefit.

- $\quad$ Live Service UC claimants are moved over to Full Service within three months of an area going live. From July 2019, all working age claimants on affected legacy benefits will begin to be moved onto Full Service through a "managed migration" process. This process should be complete by March 2023.

- Full Service UC differs from legacy benefits in a number of ways: claimants receive one monthly payment direct into their bank account; the entire payment goes to one member of the household; payment is made one month in arears and it is five weeks before claimants received their first payment; real-time earnings are used to calculate monthly UC payments; claimants are responsible for paying their rent to their landlord; and claimants have to make and manage their claim on-line.

- In Rotherham, there were 2,338 households claiming Live Service UC in December 2017 with on average of 80 new claims a month. The majority of these were single person households (92 per cent), only seven per cent received the child element, 38 per cent received the housing element and 42 per cent were in employment. The characteristics of those on Full Service UC is likely to be different than those on Live Service as it is open to a far wider group of claimants.

- In the three parliamentary constituencies that cover Rotherham, there are over 30,000 working age households claiming at least one legacy benefit. Of these, over 16,000 households claim Housing Benefit, over 16,000 households have children and over 10,000 households claim incapacity benefits. 
- Challenges for claimants and organisations in areas with Full Service UC have emerged. The evidence base from DWP on the experience of Full Service UC claimants, local responses to emerging issues, and advice from national agencies have all highlighted a number of common themes:

- Communication - raising awareness and knowledge of the UC system amongst claimants and staff within local organisations. Responses include: printed information; outreach work in the community; resources on local organisation websites; partnership working; specialist support; a communications strategy which cascades the latest information to all elements of an organisation; and making pathways to support mechanisms clear to staff and claimants. Raising awareness was particularly needed for claimants of Advance Payments, APAs, entitlement to childcare costs, support for the Verify process and rules for hours worked.

- Digital Inclusion - many claimants need support to make their initial on-line claim, ongoing support to manage their digital UC account or to obtain regular access to the internet. Certain groups are more likely to need support including older claimants and those with long-term health conditions. As increasing numbers of claimants join Full Service UC the demand for these services is likely to increase. Responses include: ensuring sufficient access to the internet is available via job centres, libraries, community organisations; providing support to claimants to increase IT skills; support for claimants in making and managing a digital claim; and ensuring claimants are aware of the requirements for managing their on-line account including the need to notify any change of circumstances.

- Financial Inclusion - a monthly payment system, varying monthly UC payments, and responsibility for paying their rent had raised challenges for many claimants with respect to money management, budgeting skills and rent arrears. Responses include: support for obtaining a bank account or joining a Credit Union; additional support services to improve Personal Budgeting Skills, money management and how to get by on a low income; advice and support for those getting into rent arrears including raising awareness of and signposting to Discretionary Housing Payments; support for those in financial difficulties including clear signposting to wider local support services such as Credit Unions, food banks, local welfare provision, local third sector agencies, Citizen's Advice Bureau etc.

- Claimants with complex needs - evidence points to vulnerable claimants or those with complex needs being less able to navigate the Full Service system. Responses include: Developing additional advice and support services for the long-term sick and disabled, care leavers, those suffering from domestic violence, and those with drug and alcohol issues; close partnership working across local service providers to support these groups; raising awareness of the appeals process and how to query or challenge decisions; and clear signposting of support services available. 


\section{Introduction}

The welfare system in Great Britain has been undergoing a major transformation since 2010. This has resulted in numerous changes to many working age benefits including the Housing Benefit system, disability benefits, and the Tax Credits system. In addition, the amount of money a household can receive across all working age benefits has been capped and the mechanism for uprating working age benefits is no-longer linked to increases in the cost of living. The changes have been wide ranging and affect households on low incomes who are in work as well as those who are out-of-work.

The reforms culminate in bringing together the main income-related benefits into a new simplified, single payment system called Universal Credit (UC). UC began to be introduced to some claimants in 2013. The design and implementation of such a major overhaul of the benefits system is not straightforward. Subsequently, the roll-out of UC has been slower and more complex than originally anticipated with the original schedule being revised at several points along the way. Presently, it is envisaged that UC will not be fully implemented until 2023 at the earliest (see Chapter 2). By that time, nearly seven million households in the United Kingdom are expected to receive UC.

In the first instance, UC was introduced via a Live Service which was only available to limited groups of new claimants. Claimants manage their claims for Live Service UC via a telephone service. Since 2016, a gradual roll-out of the Full Service UC system - which is a fully digitised system - has been underway. Claimants make and manage their claim in Full Service areas via an on-line system (see Chapter 2).

Full Service UC will be available to new working age claimants ${ }^{1}$ in Rotherham from mid-July 2018 (Chapter 3). Rotherham Metropolitan Borough Council (RMBC) has commissioned this research to support a successful and smooth roll-out of UC in the district. A rapid evidence review was undertaken to bring together the national overview of the system and reflect on the experience of other local authorities that have already undergone the transition to Full Service UC. This document aims to provide a useful resource for staff who are interacting with the new system including: council staff and those delivering operational services, housing providers, other key partners involved in support services such as the third sector service providers.

This report is set out as follows: Chapter 2 provides an overview of the national UC system including the differences between the Live Service and Full Service, and the current timetable for implementation. Chapter 3 provides a profile of working age claimants on Live Service UC in Rotherham and those yet to be moved over to UC in the area from legacy benefits. Chapter 4, details recent national research on the claimant experience of the rollout of full UC and highlights the common support needs of claimants. Finally, Chapter 5 provides national evidence and that from local service providers and/or housing organisations on key emergent issues and local support mechanisms they have put into place. Links to useful resources have been embedded within this document to signpost further evidence elsewhere.

\footnotetext{
${ }^{1}$ See Chapter 2 for a limited number of exceptions.
} 


\section{Universal Credit}

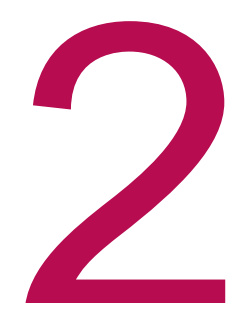

\subsection{An overview}

In 2010, the Coalition Government presented a White Paper ${ }^{2}$ outlining their plans to create a simplified working age benefits system called Universal Credit (UC). The legislative framework for UC was put in place via the Welfare Reform Act $2012^{3}$ in March 2012.

UC brings together the main means-tested social security benefits for working age people into a single payment system (Figure 2.1). This is markedly different from the previous system in place (legacy benefits) where claimants had to make separate claims for different elements of the in-work and out-of-work benefits system to different agencies: Department of Work and Pensions (DWP) administered out-ofwork benefits, HM Revenue and Customs (HMRC) administered Tax Credits, and local authorities administered Housing Benefit.

Claimants who require in-work as well as out-of-work benefits are therefore included in UC: those needing work replacement benefits due to being unemployed (previously Jobseeker's Allowance, JSA); those unable to work due to long-term sickness or disability (previously Employment Support Allowance, ESA); and those unable to work due to caring responsibilities (previously Income Support, IS). UC also covers the housing costs for households on low incomes (previously Housing Benefit, HB), support for low income families with children (previously Child Tax Credits, CTC) and those in low income work (previously Working Tax Credits, WTC).

Figure 2.1: Income-based legacy benefits replaced by Universal Credit

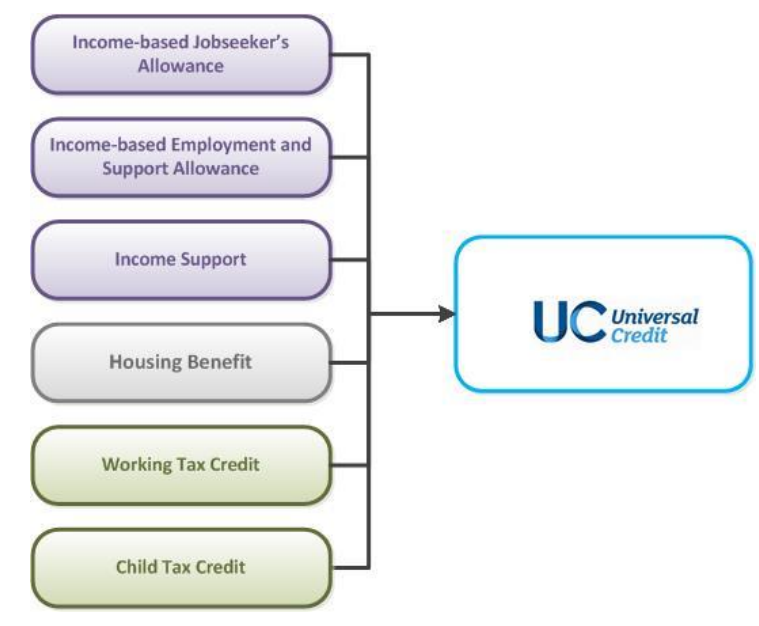

\footnotetext{
${ }^{2}$ Department for Work and Pensions (2010) Universal Credit: welfare that works, Cm 7957. London: The Stationary Office.

3 Welfare Reform Act 2012, c.5
} 
A number of benefits will be unaffected by the introduction of UC. These include contribution based JSA or ESA, Disability Living Allowance or Personal Independence Payment, Carer's Allowance, Child Benefit and Council Tax Support (see section 2.4). However, some of these benefits will count as 'unearned income' when calculating a claimant's entitlement (for more detail on this, see the Shelter Legal online guide to law for Housing Professionals which includes a Method for calculating universal credit). Claimants over pension age will continue to receive support towards housing costs through the Housing Benefit system.

\section{2. $\quad$ Live Service}

The original plans for UC were to introduce it for new claimants from 2013 and to have transferred all existing claimants onto the new system by 2017 . This proved too ambitious a plan. The timetable has been extended and re-profiled at several points since then.

New claims for those with relatively simple circumstances (for example, single claimants with no children or housing costs) were trialled in four pathfinder areas from April 2013. However, early concerns emerged about the UC IT system which had been developed by private contractors. DWP therefore decided to 'reset' the entire programme at an early stage of the roll-out in spring 2013 . They began to develop their own Digital Service (now known as Full Service) which would run alongside the original system (known as Live Service).

The Live Service continued to be rolled out gradually until it was available everywhere by April 2016. New claims could be made on-line but claimants were expected to manage all other aspects of their claim via a phone. Live Service was, however, only available to certain types of claimants who met various 'gateway conditions'. Primarily, this covered claims for being unemployed or on very low earnings (previously they would have claimed JSA). Initially, it was also only available to single claimants but in some areas at a later stage they also accepted couples. Since January 2018, no new claims to Live Service have been accepted. Eventually, all claimants on Live Service will move to the Full Service ${ }^{4}$.

\subsection{Full Service}

The full digital service began to be rolled out for new claimants across Jobcentre Districts from May 2016. It differs in a number of important ways from the Live Service:

- new claims are taken for all claimant types ${ }^{5}$ - including the long-term sick or disabled, people with children, lone parents with caring responsibilities, carers, and those in low income work or self-employment.

- it is a fully digitised service with claims made and managed on-line.

- it broadens the groups of people subject to conditionality.

The process for roll-out is gradual both geographically and across the types of claimants to be moved onto the new system. The current timetable (July 2018) is as follows:

\footnotetext{
${ }^{4}$ House of Commons Library (2018) Universal Credit roll-out: 2018-19 Briefing Paper No. 8299, London: House Commons.

${ }^{5}$ Presently there are a number of limited exceptions. This includes claims from households with three or more children who will continue to claim legacy benefits. Tenants who live in supported "exempt" accommodation can make a UC claim but their housing costs will continue to be administered via Housing Benefit.
} 
- Full Service rolled out gradually across districts for new claims from May 2016 (see exceptions footnote 5). This is expected to be implemented in all areas by December $2018^{6}$.

- As Full Service is introduced in an area, all Live Service claimants are invited to create an on-line account and attend an initial evidence interview to transfer to Full Service. All Live Service claimants in these areas are expected to have transferred to Full Service within three months of an area going "live".

- "Natural Migration" of claimants on legacy benefits to Full Service UC occurs if claimants in these areas have a change of circumstances. For example, if they have a child, get a job or move address (see exception below for those with Severe Disability Premium).

- Claimants of legacy benefits in Full Service areas can "Opt in" to Full Service UC. However, it is advised that claimants wishing to do so seek advice from a welfare rights advisor to consider the potential implications to entitlement or access to transitional protection.

- A "Managed Migration" to transfer all claimants on legacy benefits to Full Service will begin in July 2019. It is expected that nearly two million families in the UK will the transferred through this process. Most of these will either be claiming Tax Credits or Employment and Support Allowance. The timetable for this process has recently been extended to March $2023^{7}$. However, at present no further details have been given of how this will be implemented either geographically or by claimant group type.

- Transitional Protection will be available to all claimants who are moved over to UC from a legacy benefit as part of the managed migration of claimants ${ }^{8}$. This means they will not lose out in cash terms even if their entitlement is lower on UC than legacy benefits. This protection will continue (without any uprating) until either a claimant's circumstances change significantly ${ }^{9}$ or their UC award "catches up" due to annual uprating. Claimants who move onto $U C$ via natural migration are not entitled to transitional protection.

- An extension of transitional protection was made in the DWP announcement on the $7^{\text {th }}$ June (full details in footnote 7 ). This includes those who live alone and receive the Severe Disability Premium ${ }^{10}$; those taking up short-term work who have childcare costs; those where transitional protection came to an end due to a short-term increase in earnings; and Tax Credit claimants with capital in excess of $£ 16,000$ (their capital will be disregarded for 12 months from the point at which they are moved to UC).

\footnotetext{
${ }^{6}$ DWP (March 2018) Universal Credit Transition Rollout Schedule

${ }^{7}$ See written statement from the Work and Pensions Secretary, Esther McVey on 7 June 2018. See revenuebenefits June Blog.

${ }^{8}$ See revenue benefits, Universal Credit: Transitional protection.

${ }^{9}$ A significant change could include: a partner leaving or joining a household; a three month earnings drop below the level of work expected according to their claimant commitment; a member of the household stopping work; or the UC award ending.

${ }^{10}$ These claimants will not be moved to UC until they qualify for transitional protection via managed migration. Claimants who have already lost this premium as a consequence of moving to UC via a natural migration will be provided with an ongoing payment plus an additional payment to cover the period since they moved.
} 


\subsection{UC payment system}

The payment mechanisms for UC are different than for legacy benefits ${ }^{11}$. UC is a single payment which includes a standard allowance with additional entitlements related to having children, housing costs, childcare costs, caring responsibilities or having a Limited Capability for Work (LCW - see new rules below for new claims after April 2017). Some of the key differences in UC compared to the previous legacy benefits are:

- UC is paid to the claimant once a month in arrears directly into their bank account - this differs from legacy benefits which are primarily paid on a two weekly basis.

- UC is paid to one person within a household - this compares with legacy benefits where adult members of the household may have claimed and received different elements of their benefits package.

- $\quad$ There is a five week period before new UC claimants receive their first benefit payment (the six week waiting period was scrapped from February 2018).

- $\quad$ Late Payments - not all Full Service UC first payments are paid on time or in full which can cause financial hardship for some claimants. Although the timeliness of payments has improved over time, the latest DWP data for February 2018 shows that for new claims:

- $\quad$ only 83 per cent received full payment on time

- 94 per cent received full payment within 4 weeks of the payment due date

- 97 per cent received full payment within 8 weeks of the payment due date

The proportion new claims receiving some of their payment on time is slightly higher with:

- 90 per cent received some payment on time

- 99 per cent received some payment within 4 weeks of the payment due date.

- Advance Payment - from January 2018 claimants who face financial hardship due to the five week wait for their first UC payment can request a Universal Credit Advance payment. This is a loan up to 100 per cent of any expected benefit payment. It has has to be paid back from UC payment over time and relies on an affordability assessment. Normally, the advance has to be paid back within a six-month period (but this can be extended to 12 months). Benefit advances can be high risk for those who have pre-existing debts.

- $\quad$ Real Time Information - the UC system is based on current monthly income. It is linked to the HMRC Pay as You Earn (PAYE) system for employees. Those who are self-employed are expected to report all payments into and out of their business at the end of each monthly assessment period. This means UC awards fluctuate monthly if there is any change in income. This contrasts with the previous Tax Credits system where awards were based on annual income then adjusted retrospectively the following year.

\footnotetext{
${ }^{11}$ Devolution means that in Scotland and Northern Ireland the payment system is being amended so that payment can be on a two-weekly basis, across more than one person in a household and housing entitlement continues to be paid direct to social landlords as a default.
} 
- Work Allowance - is the amount a claimant can earn before their UC payment is affected. Work allowances were reduced in April 2016 and claimants without children (unless they have limited capability to work) are no longer entitled to a work allowance. Claimants with children or with a limited capability to work due to ill health or disability receive a higher or lower work allowance depending on whether they receive help towards their housing costs. At April 2018 these were as follows:

- Higher Work Allowance - for claimants with children or limited capability to work with no help towards their housing costs. They can earn $£ 409$ a month before their UC award is reduced.

- $\quad$ Lower Work Allowance - for claimants with children or limited capability to work with a housing entitlement. They can earn £198 a month before their UC award is reduced.

- Minimum Income Floor (MIF) - self-employed UC claimants are expected to earn a minimum amount (the MIF) after one year of starting their business. The MIF is used in calculating a UC award and is equivalent to what an employed person in similar circumstances would be expected to earn if they were on a minimum wage. If self-employed earnings are more than the MIF then their award is calculated on the basis of their actual earnings. If a claimant earns less than the MIF then their award is calculated accordingly and they may need to find extra work to top up their earnings ${ }^{12}$.

- $\quad$ Single Taper - earned income from employment or self-employment reduces a UC award at a constant rate after any work allowance has been taken into consideration. Since April 2017, this has been 63 pence for each pound earned. Unearned income (see above) reduces a UC award on a pound for pound basis.

- Two child limit - it was announced in the 2015 Summer Budget that the child element of new UC claims after April 2017 would be limited to two children. The first child premium is also no longer available since April 2017. These changes also apply to Child Tax Credit (CTC) claims after this point. There are a limited number of exceptions to these rules and varying transitional protection for existing claimants depending on whether the claim is made in the interim period (until $31^{\text {st }}$ January 2019). For families with three or more children making a claim in a Full Service area during the interim period this will still have to be made to CTCs. See full details of the current rules below ${ }^{13}$.

- There is no Severe Disability Premium in UC. This has caused issues for some long-term sick or disabled claimants who have moved over to UC through a natural migration triggered by a change in circumstances. See footnotes 7 and 10 for new guidance on transitional protection being offered to this group. Claimants with SDP or making a claim for the Carers element of UC for someone in receipt of SDP should first seek advice from a welfare rights advisor.

- $\quad$ Since April 2017, UC claimants no longer receive an additional entitlement for being in the Limited Capability to Work (LCW) group. This is also the case for new ESA claimants after this point in time. This does not affect claimants who made their claim before April 2017, transfer over to UC LCW via a managed migration from the ESA WRAG, or who are assessed as having Limited Capability for Work and Work Related Activity (LCWRA - equivalent to the ESA Support Group).

\footnotetext{
${ }^{12}$ See revenue benefits detailed explanation of Minimum Income Floor.

13 revenue benefits $\underline{\text { UC } 2 \text {-child limit. }}$
} 
- In most cases, the LCW element will not be included in the UC award straight away. There is a three month waiting period which will begin after evidence of having limited capability for work has been provided.

- $\quad$ Direct payments for housing entitlement - the default payment mechanism for tenants living in the social rented sector was for Housing Benefit to be paid directly to their social landlord. Under Full Service UC the housing entitlement element is paid directly to the claimant as part their monthly UC payment. The claimant is then responsible for paying rent to their landlord.

- Free School Meals (FSMs) - continue to sit outside UC and must be claimed for separately. Under the legacy benefits system FSMs were a passported benefit for claimants of IS, income-based JSA or ESA, those receiving the maximum CTC award and no WTC payment. New rules introduced from April 2018 now link eligibility for UC claimants to FSMs as having an earned net income of $£ 7,400$ or less after income tax and National Insurance contributions ${ }^{14}$. In recognition that some families would miss out ${ }^{15}$ on entitlement to FSMs due to this change. Transitional protection has now also been put in place until UC until UC is fully implemented.

- Council Tax Support (CTS) - this continues to sit outside UC and must be claimed for separately via a localised CTS system which is administered by the local authority.

- Increased conditionality - claimants within the UC system are expected to sign a Claimant Commitment and adhere to a specific conditionality regime depending on their circumstances. These include work-related activities in order to get entitlement to UC. Partners of claimants also have to agree to their own claimant commitment. The system (unlike Tax Credits) also includes in-work conditionality. Potentially, the conditionality regime may put more claimants at risk of being sanctioned or losing access to their benefits for specified periods of time. Claimants are allocated to one of four conditionality groups depending on their circumstances:

- $\quad$ all work-related requirements - they are expected to do all that they can to find a job or get a higher paid job. This includes job search, applying for jobs and attending job interviews.

- $\quad$ work-focused interview and work-preparation requirements - these claimants are not expected to look for work but they are expected to attend work-focused interviews with their Work Coach and prepare for work. For example, activities might include: CV preparation, training, work experience etc.

- work-focused interview requirements only - claimants are expected to attend interviews with their Work Coach to prepare for work in the future, but they are not expected to apply for jobs or prepare for work at the present.

- no work-related activity requirements - this group is not subject to conditionality and are not expected to undertake activities to prepare for or look for work.

Claimants within each of these conditionality groups are then allocated to one of six Labour Market Regimes (LMR): Intensive Work Search; Light Touch; Work Preparation; Work Focused Interviews; No Work Related Requirements; and Working Enough. This depends on whether their income is above or

\footnotetext{
${ }^{14}$ Department for Education (2018) Free School Meals: Guidance for local authorities, maintained schools, academies and free schools, London: Department of Education.

${ }^{15}$ Joyce, R. and Waters, T. (2018) Free School Meals Under Universal Credit, London: Institute of Fiscal Studies.
} 
below the Administrative Earnings Threshold (AET) or the Conditionality Earnings Threshold (CET).

These features of UC are part of an underlying policy rationale which has increased conditionality and the responsibilities of claimants. By making a single monthly benefit payment via a bank transfer UC aims to make claimants more aware of their monthly income and align the experience to receiving a monthly income from work. In turn, this means claimants have to be responsible for managing a monthly budget including paying their rent and having to make difficult decisions about what accommodation they can afford. The new system is also designed to make it easier for claimants to undertake any paid work - no matter how few hours this may be and ensure they are better off in work.

However, some of these design elements have subsequently caused hardship for some UC claimants including: the five week delay for a first benefit payment; fluctuating payments due to real time reporting of incomes which when combined with precarious employment or fluctuating work hours can be difficult to manage; rent arrears due to the removal of direct payment of the housing element to the landlord; and not having access to a bank account.

Issues around the UC design features have also been compounded by changes to eligibility, entitlement and the value of legacy benefits relative to the cost of living which are incorporated within the UC system. Changes announced to UC since its original inception have also reduced entitlement via reduced work allowances, a minimum income floor for the self-employed, and a two child limit for the child element for children born after April 2017. 


\section{Full Service UC in Rotherham}

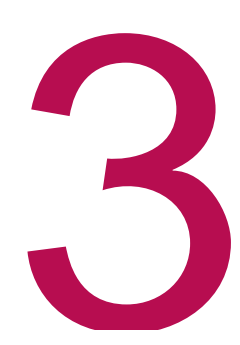

\subsection{Introduction}

The roll out of Full Service UC across the country has increased in pace since spring 2018. As of 12 April 2018, it had been rolled out to 258 of all 638 jobcentres (40 per cent) ${ }^{16}$. The planned schedule of roll-out continues until December 2018 (footnote 6) and by the end of June 2018 a further 113 jobcentres had Full Service up and running - 58 per cent of all.

There are three jobcentres which cover the great majority of residents in Rotherham all of which will go live with Full Service UC for new claims from mid-July 2018. All existing Live Service UC claimants in these job centres will be expected to move over to the Full Service within three months of this date:

- Rotherham JCP

- Maltby JCP

- Dinnington JCP.

This chapter profiles the claimants on Live Service UC and key legacy benefits in Rotherham to provide an indication of the number and types of claimants likely to be affected by the new system. The data is taken from DWP working age benefits available from NOMIS ${ }^{17}$; UC and Housing Benefit Data available from DWP StatXplore $^{18}$ and the House of Commons Library Universal Credit on-line Constituency Data Tool ${ }^{19}$.

\subsection{Live Service UC claims in Rotherham}

Rotherham has had some Live Service UC claimants since September 2015. However, the numbers were very small (less than 20 claimants) until January 2016 when the flow gradually increased (Figure 3.1). By December 2017, there were 2,338 households claiming UC in Rotherham containing 2,369 UC claimants ${ }^{20}$. On average, only about two thirds of these households received an actual UC payment in any given month. Households may not have been in payment if, for example, earnings for the period are sufficiently high to take a household out of Universal Credit entitlement.

\footnotetext{
${ }^{16}$ National Audit Office (2018) Rolling Out Universal Credit, London: National Audit Office.

${ }^{17}$ NOMIS - An on-line portal containing ONS official labour market statistics.

18 DWP Stat-Xplore - An on-line portal containing data on a range of DWP benefits.

19 Constituency data: Universal Credit roll-out - A House of Commons Library data tool with constituency level data on the Universal Credit roll-out.

${ }^{20}$ Provisional data for May 2018 indicates that the number of UC claimants had risen to $2,535$.
} 
Figure 3.1: Live Service UC households in Rotherham, 2015-2017

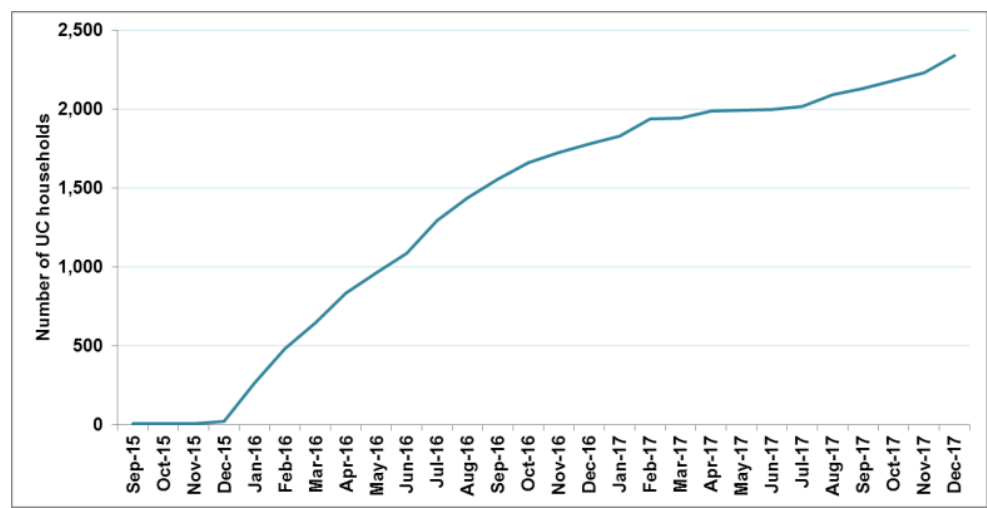

Source: DWP Stat-Xplore

In December 2017, the vast majority of Live Service UC households were single person households (92 per cent); only four per cent were lone parent families; and three per cent were couples with children. Approximately a third of claimants were aged under 25 and about half were aged 25-49. This profile by age and household composition therefore reflects the original gateways for UC Live Service. Other characteristics of the Rotherham UC Live Service were as follows:

- Only 38 per cent of UC households received the housing element (890 households); this comprised of:

- 24 per cent of UC households receive the housing element and live in the social rented sector; 34 per cent of whom had a direct payment to their landlord.

- 14 per cent of UC households receive the housing element and live in the private rented sector; six per cent of whom had a direct payment to their landlord.

- $\quad$ Seven per cent received the child element (150 households).

- $\quad$ Only two per cent had the carer element - this is only available to those with substantial caring responsibilities for a disabled person of 35 hours or more a week.

- 42 per cent were in employment.

- 58 per cent were in the all work-related requirements conditionality group ${ }^{21}$; one out of five of these were already in employment.

- In the six months to December 2017, there were on average 80 new claimants who had completed their UC claim process and accepted their Claimant Commitment.

\subsection{Legacy benefit claimants in Rotherham}

By December 2017, less than 10 per cent of claimants were on UC Live service in Rotherham. This compares with the picture for Great Britain where approximately 11 per cent of all claimants were on UC. Therefore, the majority of working age claimants in the area were still on legacy benefits at this point. In November 2017, in Rotherham there were:

${ }^{21}$ Claimants in this group are required to search for work and take action to secure work (or more/better paid work). 
- $\quad 2,700$ JSA claimants.

- 12,790 ESA claimants ${ }^{22}$.

- 2,140 Lone Parent Income Support claimants.

- $\quad$ 1,350 Carers receiving Income Support.

- 21,200 families receiving Tax Credits of which: 15,000 are in work; 6,200 are out-of-work; and 18,700 have children.

- $\quad 14,750$ working age households in receipt of Housing Benefit of which 10,100 social rented sector tenants and 4,650 are private rented sector tenants. There are a further 6,520 Housing Benefit claimants who are above pensionable age and will not move over to the UC regime.

Some of these claimants will be on contribution based JSA and ESA rather than income based and so will not transfer to UC. These groups are also not mutually exclusive as claimants can receive more than one of these benefits. For example, a claimant could potentially receive JSA, Housing Benefit and Tax Credits. This means that the number of claimants who will move over to UC will be less than the sum of above.

\subsection{Rotherham constituency data for Universal Credit roll-out}

The House of Commons Library has released a user-friendly on-line tool to estimate for all parliamentary constituencies the UC caseload when Full Service has been fully rolled-out. The estimates take into account of the overlapping nature of benefits to derive the actual number of households that will be on UC rather than just the number of claimants receiving legacy benefits in these areas currently ${ }^{23}$.

There are three Parliamentary Constituencies (PCs) which cover Rotherham district: Rotherham, Rother Valley, and Wentworth and Dearne. Claimants in Rotherham PC will all be seen in Rotherham Jobcentre Plus (JCP). Of the claimants in Rother Valley: 40 per cent will be seen in Dinnington JCP; 30 per cent in Maltby JCP; and 30 per cent in Rotherham JCP. The distribution of claimants across job centres in the Wentworth and Dearne PC is more complex. This PC covers two wards in Barnsley whose residents attend the Goldthorpe Jobcentre Plus ${ }^{24}$ and claimants from Brampton attend the Wombwell JobCentre Plus. Residents from the Swinton and Wath wards attend the Mexborough Jobcentre Plus in Doncaster ${ }^{25}$. The House of Commons Library on-line tool for Universal Credit roll-out estimates that 30 per cent of Wentworth and Dearne PC claimants will attend Rotherham JCP and a further 10 per cent will be seen by Maltby JCP.

Table 3.1 presents constituency estimates of the caseload at December 2017 of Live Service UC or those on legacy benefits yet to move over to Full Service. These figures therefore include some claimants in Wentworth and Dearne PC that may be resident or attend job centres outside the borough. The data shows that:

- Less than one in ten households who will eventually be on UC are currently on the system.

- The gateway to Live Service UC means that the current UC caseload is mainly unemployed claimants.

\footnotetext{
22 This includes 330 claimants who are on Incapacity Benefit or Severe Disablement Allowance.

${ }^{23}$ All other things remaining constant. Full methodology can be seen in: House of Commons Library (2018) Universal Credit roll-out: 2018-19 Briefing Paper No. 8299, London: House Commons.

${ }^{24}$ Rolled out Full Service in July 2017. 30 per cent of Wentworth and Dearne claimants attend Goldthorpe JCP.

${ }^{25}$ Rolled out Full Service in Oct 2017. 30 per cent of Wentworth and Dearne claimants attend Mexborough JCP.
} 
- The profile of claimants yet to move from legacy benefits to UC are more likely to have children, long-term ill health or disabilities, and entitlement for housing support compared to the current UC caseload.

Table 3.1: Rotherham Parliamentary Constituencies: Households on UC and those on legacy benefits yet to move to UC

\begin{tabular}{|c|c|c|c|}
\hline \multirow[b]{2}{*}{ Type of support } & \multicolumn{2}{|c|}{ Number of households } & \multirow[b]{2}{*}{$\%$ on UC } \\
\hline & Universal Credit & Legacy Benefits & \\
\hline \multicolumn{4}{|c|}{ Rotherham Parliamentary Constituency } \\
\hline Housing & 400 & 7,040 & $5 \%$ \\
\hline Children & 30 & 6,480 & $0 \%$ \\
\hline Incapacity & 30 & 4,200 & $1 \%$ \\
\hline Unemployment $^{1}$ & 570 & 1,200 & $32 \%$ \\
\hline Total households & 970 & 12,340 & $7 \%$ \\
\hline \multicolumn{4}{|c|}{ Rother Valley Parliamentary Constituency } \\
\hline Housing & 160 & 3,680 & $4 \%$ \\
\hline Children & 20 & 4,520 & $1 \%$ \\
\hline Incapacity & 20 & 2,340 & $1 \%$ \\
\hline Unemployment $^{1}$ & 360 & 500 & $42 \%$ \\
\hline Total households & 620 & 7,760 & $7 \%$ \\
\hline \multicolumn{4}{|c|}{ Wentworth and Dearne Parliamentary Constituency ${ }^{2}$} \\
\hline Housing & 760 & 5,550 & $12 \%$ \\
\hline Children & 370 & 5,440 & $6 \%$ \\
\hline Incapacity & 60 & 3,540 & $2 \%$ \\
\hline Unemployment ${ }^{1}$ & 880 & 700 & $56 \%$ \\
\hline Total households & 1,500 & 10,250 & $13 \%$ \\
\hline \multicolumn{4}{|l|}{ Total } \\
\hline Housing & 1,320 & 16,270 & $8 \%$ \\
\hline Children & 420 & 16,440 & $2 \%$ \\
\hline Incapacity & 110 & 10,080 & $1 \%$ \\
\hline Unemployment ${ }^{1}$ & 1,810 & 2,400 & $43 \%$ \\
\hline Total households & 3,090 & 30,350 & $9 \%$ \\
\hline
\end{tabular}

This is number of people rather than number of households.

2 This includes the whole PC and some of these claimants will have their claim at Goldthorpe JCP or Mexborough JCP which already rolled out Full Service UC in 2017.

Source: House of Commons Library 


\section{Roll-out of Full Service UC}

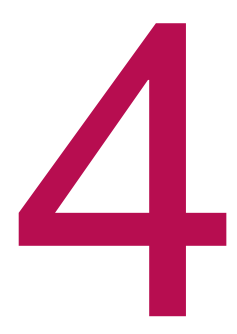

\subsection{Test and learn approach}

Universal Credit has struggled with a number of operational challenges since its original inception in 2010 and gradual implementation of Live Service UC since 2013. DWP "reset" the project in 2013 in recognition of these issues. At this point it was decided that a twin-track approach would be taken. A new digital system for Full Service UC was designed in-house by DWP and since May 2016 this has gradually been rolled-out alongside the Live Service UC. Live Service was closed to new claims in December 2017 and is expected to be decommissioned by July 2019. A recent report published by the National Audit Office in June 2018 has fully documented the issues with the design and implementation of $\mathrm{UC}^{26}$.

The gradual roll-out of Full Service UC has taken a test-and-learn approach. This allows DWP to learn from the experience of running the live system, to improve the design and functionality of the system and the readiness of the services that support the system. This has included DWP responding to feedback from social landlords and local authorities to develop the landlord portal to speed up the verification of claimants' social rent details. In the November 2017 Budget, other policy changes were announced in response to evidence of hardship being felt by some claimants due to the operation of the system. This included removing the initial 7-day waiting period, an increase in the advance amount a claimant could receive and extending the repayment period and including a two-week run-on for claimants in receipt of Housing Benefit.

\subsection{DWP survey of Full Service claimants}

The government published a detailed survey of Full Service claimants in June 2018. The survey interviewed claimants at three months and eight months after their claim. Unless otherwise specified the figures below are for wave one of the survey. A selection of the key findings from the report are given below to provide a profile of the characteristics of claimants and their experience of accessing Full Service UC. A number of important issues were highlighted which inform the additional support requirements that some claimants may need.

\section{Characteristics of UC claimants}

- 44 per cent included children in their claim.

- 41 per cent of claimants had a long-term health condition.

\footnotetext{
${ }^{26}$ National Audit Office (2018) Rolling Out Universal Credit, London: National Audit Office.
} 
- 59 per cent of claimants had received some form of in-work or out-of-work benefits before their UC claim.

- 29 per cent were in work at the start of their UC claim.

- 35 per cent had never been in work; this rises to 44 per cent of those with long-term health conditions.

\section{Access to the internet}

- 58 per cent had access to the internet at home via a computer.

- 31 per cent had access via a mobile phone.

- 7 per cent had regular access elsewhere (libraries, community centres and JobcentrePlus).

- 4 per cent had no access or irregular access to the internet.

\section{Difficulties in making an on-line claim:}

- Only just over a half of all claimants (54 per cent) were able to make an online claim on their own.

- A further fifth (21 per cent) were able to make an on-line claim but needed help from someone to make a claim. Of these:

- 60 per cent had help from their spouse, family or friend.

- 15 per cent received help from their local council via Universal Support, their housing officer or their social worker.

- A fifth (20 per cent) were not able to make an on-line application either on their own or with help and had registered their claim in a Jobcentre Plus with assistance from their Work Coach

- This was more common amongst claimants who had no access or irregular access to the internet (48 per cent).

- Nearly a third (30 per cent) of those making an on-line claim found the process difficult; this rises to 38 per cent of those with a health condition.

- Nearly a third (32 per cent) of those who made an on-line claim said their greatest difficulty was gathering all the documentation needed; the second most common difficulty on-line claimants had was inputting their housing costs (28 per cent); 12 per cent found the proof of residency/Habitual Residency Test difficult.

- $\quad 43$ per cent of claimants felt they needed more support to set up their UC claim and 30 per cent felt they needed more ongoing support using their UC account.

\section{Using the UC Service Centre}

- $\quad 39$ per cent of claimants contacted the Service Centre for help before making a claim.

- 45 per cent contacted the Service Centre whilst completing their claim.

- 60 per cent contacted the Service Centre after submission of their claim.

- Just over a quarter (26 per cent) of those who had called the Service Centre for help felt that their call was not dealt with very well. 


\section{Using Verify}

- Nearly half of claimants (45 per cent) had used the Verify service to confirm their identity on-line.

- 30 per cent of claimants had not been successful in their attempt to confirm their identity with Verify.

- Nearly half (48 per cent) of those who had used or attempted to use Verify had found it difficult to use.

\section{Understanding of Universal Credit}

- The survey findings show that there is scope to improve the knowledge of claimants on how UC works:

- Nearly four out of ten claimants did not know that however many hours they work they can still receive UC if they are on low income

- 29 per cent simply did not know

- 10 per cent believed this to be untrue.

- Around half (51 per cent) of claimants agreed that, compared with only being on benefits, that for every hour they work would leave them better off under UC due to the single Taper.

- One in ten claimants had been sanctioned, and this was more common among male claimants and younger claimants. The most commonly cited reason for sanctioning was failing to attend a work focussed interview.

\section{Budgeting and managing finances}

- Nearly a third of claimants were not confident in managing their monthly UC payment:

- This changed little over the course of the claim with 31 per cent lacking confidence at three months into their claim and 32 per cent saying this was the case eight months into the claim.

- Those with long-term health conditions were less likely to be confident managing their money than those without health conditions:

- 57 per cent of those with health conditions were confident compared to 75 per cent of those without health conditions.

- The confidence of those with long-term health conditions did not improve over the two waves of the survey.

- $\quad$ Claimants were asked in both waves of the survey about their ability to keep up with bills and credit commitments, this changed little over time:

- only a quarter said they were keeping up without any difficulties in both wave 1 and wave 2 .

- 28 per cent in wave 1 said they were keeping up but that it was a struggle from time to time (increased to 32 per cent in wave 2).

- 14 per cent in wave 1 said they were keeping up but that it was a constant struggle (12 per cent in wave 2).

- 12 per cent in wave 1 said they were falling behind with some bills/credit commitments (13 per cent in wave 2).

- 18 per cent in wave 1 were having real financial problems (15 per cent in wave 2). 
- The extent to which people were in financial difficulties differed by claimant characteristics. There were also indications that for many groups they got a little better with financial management over time:

- older claimants were more likely to be in financial difficulty than younger claimants

- 58 per cent of over 55 year olds were in financial difficulty in wave 1; but this had fallen to 47 per cent in wave 2 .

- 50 per cent of 35-54 year olds were in financial difficulty in wave 1; but this had fallen to 46 per cent in wave 2 .

- 34 per cent of 16-34 year olds were in financial difficulty in wave 1; this increased to 35 per cent in wave 2.

- Claimants with long-term health conditions were more likely than those without to be in financial difficulty:

- 54 per cent of those with a long term health condition were in financial difficulties in wave 1; this had fallen to 50 per cent at wave 2.

- 35 per cent of those without a long term health condition were in financial difficulties in wave 1; this had fallen to 33 per cent at wave 2.

- Half of all claimants who were interviewed for wave 2 of the survey had obtained additional funds on top of UC to help them get by:

- $\quad$ This rose to 63 per cent for those who had got into financial difficulties.

- A third had got money from friends or family.

- 13 per cent had got an advance from JCP or DWP.

\section{Housing and managing housing payments}

- 83 per cent of claimants had housing costs.

- Nearly a third (30 per cent) were renting from a private landlord.

- One quarter of claimants were renting from the council.

- 15 per cent were renting from a Housing Association.

- $\quad$ The majority (84 per cent) of claimants receiving a housing payment (at wave 2) were confident of making sure their housing costs were paid:

- 55 per cent were very confident

- 29 per cent fairly confident

- 9 per cent were not very confident

- 7 per cent were not at all confident.

- $\quad$ Confidence of ensuring housing costs were paid was lower amongst those experiencing financial difficult:

- 67 per cent for those struggling to keep up with bills or credit commitments

- 73 per cent for those with rent arrears

- 78 per cent for those with an APA.

- 36 per cent of those paying for their accommodation in wave 1 were in arrears; this barely changed by wave 2 ( 35 per cent)

- 23 per cent of claimants in wave 1 were in arrears and were also not keeping up with their bills/commitments; this was virtually unchanged in wave 2 (22 per cent) 
- $\quad$ a further 13 per cent (wave 1) were in rent arrears but were keeping up with other payments; there were 12 per cent in this group in wave 2.

- Claimants with a long-term health condition, tenants in the social rented sector, those with an advance payment or an Alternative Payment Arrangement ${ }^{27}$ (APA) in place were more likely to be in arrears than those who were not.

- Just over a fifth (22 per cent) of claimants had an APA in place by wave 2 of the survey:

- $\quad 48$ per cent of those with an APA had requested this themselves

- 37 per cent said their landlord had suggested an APA

- $\quad$ eight per cent said their Work Coach had suggested an APA.

- Of those with housing costs arrears, nearly two thirds (65 per cent) said these began after making a claim for UC.

- Eight per cent of claimants who took part in both waves of the survey had moved during the period; one fifth of these said it was because their UC payments were not enough to cover the cost of their previous accommodation.

\section{Childcare costs}

- 44 per cent of claimants had at least one child included in their claim.

- 41 per cent of those with children were not aware that they could claim back 85 per cent of childcare costs.

- Nearly a fifth (18 per cent) of those with children in the wave 2 top-up survey sample paid for formal childcare.

- Only two thirds of this group (those with formal childcare costs) were claiming back these costs.

- 42 per cent of those who had claimed back childcare costs were unsatisfied with the experience.

\subsection{Summary of findings and additional support needed}

The DWP survey of claimants points to a number of areas that Full Service UC claimants may require additional support:

- having regular access to the internet

- $\quad$ support in making an on-line claim

- $\quad$ on-going support with managing their digital claim

- $\quad$ support for the Verify process

- $\quad$ support for managing on a low income and budgeting skills

- $\quad$ advice and support for those getting into rent arrears

- $\quad$ support for those in financial difficulties including signposting to wider local services such as Credit Unions, food banks, local welfare provision, local third sector agencies, Citizen's Advice Bureau etc.

\footnotetext{
${ }^{27}$ APAs are available for claimants who struggle to manage their housing payments. These are set up by DWP if a claimant is two months or more in rent arrears or if the claimant has continually underpaid their rent and accrued rent arrears equivalent to one months' rent.
} 
- raising awareness amongst claimants as to the rules of the new system including:

- rules about hours worked

- entitlement for childcare

- how to get an APA

- $\quad$ how to get an advance payment or extend the payback period.

Overall, the DWP evidence points towards certain groups finding the transition to Full Service UC more difficult than others. This includes claimants with long-term health conditions and older claimants. There will also be a certain amount of cross over between these two groups. These claimants tend to need more support for making an on-line claim as well as with the ongoing management of their claim, are less confident about understanding and managing UC payments, and have a greater likelihood of falling into financial difficulties and housing arrears. Potentially designing local support services, advice and guidance specifically for these groups may help them navigate the system and reduced the chance of them falling into financial difficulties and rent arrears.

The next chapter details how various local and national organisations have responded to the roll-out of Full Service. This provides insights of the strategies put in place for supporting tenants and residents as they engage with the new system. 


\section{National and local evidence on Full Service}

\subsection{Introduction}

The roll-out of Full Service UC in an area is a gradual process. New claimants of income based working age benefits begin to be taken via Jobcentre Plus on a given day. This includes new working age claimants needing to claim support for housing costs. Existing Live Service claimants are expected to have moved over to the new system within three months of an area going live. Some existing claimants will also gradually move over to Full Service via a natural migration process if their circumstances change. In the longer run, all those on working age income based legacy benefits are expected to be moved over to Full Service via a managed migration by 2023 .

The process is therefore not instantaneous and it takes a while for the system to bed in locally. During the initial stages of roll-out of Full Service in an area this leads to extra training needs and demands on the staff involved. At the very front end of service delivery this can mean Work Coaches in Jobcentre Plus have heavy demands on their time to do with the change in system and moving claimants across to the new system. Therefore, claimants may seek advice and support to do with their claim from other agencies they engage with - for example, their housing provider, council or Citizen's Advice Bureau.

The evidence base on the impacts of, and responses to, the national roll-out programme for Full Service UC is therefore at a relatively early stage. However, much of the national research and recommendations on how organisations can help support clients going onto the new system chimes with the findings from the DWP Survey of Claimants discussed in Chapter 4.

\subsection{Child Poverty Action Group}

The Child Poverty Action Group (CPAG) have set up an Early Warning System on their website to gather information and case studies from people in policy and practice on the impact of welfare reform on children and families across the UK. CPAG have produced a July 2018 report $^{28}$ specifically on issues reported to do with Universal Credit claimants. These include claimants being given the wrong information, decisions made in error, and vulnerable claimants having to resort to foodbanks as a result. CPAG also report that many of the problems arise repeatedly as more claimants claim via the new system.

\footnotetext{
${ }^{28}$ Child Poverty Action Group (2018) CPAG's early warning system - report on universal credit top issues, London: CPAG.
} 
The full report is accompanied by a blog which provides an overview of the key findings. These include examples of claimants who had issues with:

- Administrative Errors - this was the reason for more than one in three of the cases reported. These included the DWP not applying the law correctly when making a decision; lost evidence; claimants given the wrong information; and issues to do with entitlement or WCAs for ESA claimants being moved over to UC. Lots of administrative errors have also been reported in relation to housing entitlement.

- Digital Exclusion - as with the DWP survey of claimants CPAG reports people being unable to make or manage their claim because they either did not have the IT skills or access to a computer or smart phone. For those accessing the internet from the library or voluntary services sometimes the access was restricted or they needed more IT support.

- Delays - in processing documents, decisions for hardship loans or reversing/responding to queries about decisions.

- Non-response to queries - when claimants have left them in their on-line journal or via the helpline. Welfare rights advisers were also having difficulties intervening on behalf of UC clients as 'implicit consent' for an adviser to speak to DWP on behalf of a client is no longer recognised.

- $\quad$ Challenging claim decisions - CPAG had seen a number of cases where the right to challenge decisions had effectively been refused.

\subsection{Trussell Trust}

The Trussell Trust operates a network of food banks across Britain. The organisation has been at the forefront of campaigns to raise awareness of those who resort to emergency food parcels as a result of the effects of welfare reform. The Trussel Trust produced a report ${ }^{29}$ on the early impacts of the roll-out of both Live Service and Full Service UC areas where they have foodbanks. The key findings include:

- An increase in foodbank referrals in areas with UC was more than double the national average (17 per cent versus 7 per cent).

- The six week waiting period (since reduced to five weeks) was leading to food bank referrals, debt, mental health issues, rent arrears and eviction. These effects can last even after receiving a UC payment due to bills and debts mounting up.

- People in insecure or seasonal work are particularly affected.

- Navigating the digital system and making an on-line claim can be difficult for people struggling with computers.

\subsection{National Housing Federation}

The National Housing Federation website has a Universal Credit Resources section which includes commonly asked questions and a number of research papers. This includes a report produced in the early stages of roll-out of UC: Universal Credit One Year In: The experiences of Housing Associations. Although this was produced prior

\footnotetext{
${ }^{29}$ Trussel Trust (2017) Early Warnings: Universal Credit and Foodbanks, London: Trussel Trust.
} 
to the main roll-out of Full Service many of the top tips and key recommendations for preparing tenants, staff and organisations still hold:

- Communication - focusing on raising awareness of Full Service UC, how it works, who it affects and where to get support. This was done via post and on housing providers' websites. Communications also focused on encouraging tenants to tell their landlord when they make a Universal Credit claim and promoting a culture of prioritising rent payment.

- Roadshows, information events and information stands - outreach events in the community to raise awareness and signpost support services. Some Housing Associations located information stands in local shopping centres. This can be a useful way to meet tenants and discuss changes face to face, but may only speak to a small part of the population.

- $\quad$ Specialist UC staff - all staff needed to have good training and awareness of UC, how it works and who it affects. Having specialist staff with a responsibility for UC and who understood the detailed intricacies of UC was also useful found to be useful. This supported the cascading of the latest information on the system as it evolving to other staff. It also provided a referral point for tenants who had complex circumstances, had difficulties with their claim or needed further support.

- Mobile working - Several Housing Associations were equipping staff for mobile working to allow staff to better support tenants in their neighbourhoods and own homes.

- Preparing the organisation - using holistic organisational approaches so all parts of an organisation are aware of the changes and keep up to date with the on-going changes to the system as each element of change occurs. Requires regular and effective communication channels throughout the organisation (bottom-up as well as top-down). Ensuring all elements of the organisation know where to signpost claimants or staff to in order to access additional support service both within their organisation and in partner organisations.

The Scottish Federation of Housing Associations also has a section of their website dedicated to information on upcoming issues for social housing providers with roll-out of Full Service UC. This flags up some important issues to do with the verification process for housing costs:

- Live Service UC claimants will be expected to make a fresh claim when they move over to Full Service. This includes the claimants re-declaring their housing costs and landlords verifying for housing costs. This was flagged up in the National Audit Office report as one of the issues causing delayed payments for new claims (see footnote 26).

- Re-verification of housing cost requests will be handled in one of two ways: landlords who are enrolled on the Landlord Portal will receive requests via the portal; landlords who are yet to be offered enrolment onto the Portal will receive an email request.

- DWP partnership managers will support landlords in preparing for this activity.

\subsection{DWP resources}

DWP have produced a number of guides for landlords to support the roll-out of Full Service UC. These were updated on the $13^{\text {th }}$ July 2018: 
- Universal Credit and rented housing: guide for landlords

- Universal Credit service charges - guidance for landlords

- Universal Credit housing costs and disclosure: guide for landlords

- Social rented sector: reporting April 2018 rent changes: advice for landlords

- Personal Budgeting Support and Alternative Payment Arrangements

DWP have also launched a new website to help people understand what Universal Credit means for them. This contains information that is useful for both claimants and partner organisations:

- Understanding Universal Credit

The Government has also launched a Social Security Advisory Committee (SSAC) public consultation on proposals for moving all existing claimants of a working age income-related legacy benefits to Universal Credit:

- $\quad$ consultation for managed migration of claimants

\subsection{Useful resources}

There are number of useful websites that give very detailed information on the implications and rules for UC for specific types of claimants or households. Many of these websites also provide regular updates on the progress of the Full Service rollout and highlight any implications this may have for claimants or staff interacting with the system. Click on the icons below for links to a selection or resources:

- revenuebenefits

- tURnzUS

- entitledto

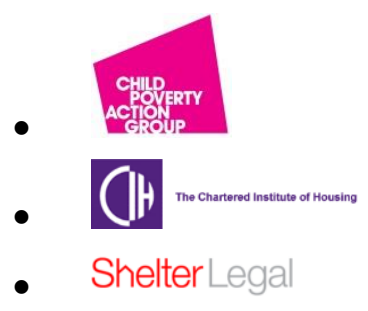

\subsection{Local responses to Full Service}

Many local authorities have already gone through the transition to Full Service. The local approaches taken by many of these areas echo the key messages from national organisations above:

- Communication - aimed at increasing awareness of Full Service UC and how local support services can ease the transition for tenants and residents. This has primarily been through mailouts, dedicated section on local authority website and information events.

- Briefings to increase organisational awareness - including regular communication meetings across teams; briefing notes and local research; training; and working with partner organisations. 
- $\quad$ Clear signposting of wider services - making sure staff in local authority know where to signpost claimants to for wider support mechanisms including Discretionary Housing Payments, debt and money management advice, food bank provision, welfare rights advice, open access digital provision and support etc.

- Support for vulnerable claimants or complex needs - initial evidence points towards those with health issues, older claimants, those in complex situations e.g. suffering from domestic violence etc. Developing or signposting local service provision which support these groups can therefore be beneficial.

\section{A Case Study: Manchester City Council}

Full Service UC began to be introduced across Manchester in late 2017. Their final tranche of job centres will move over at the end of July 2018. The council has a UC Project Plan, a series of external communications for UC customers, internal briefings and documentation for staff, and resources available on their website. Processes, support services and resources include:

- A Welfare Reform Board - monitors the impact of the implementation of UC and delivery of the project plan.

- A Universal Credit Working Group - consists of key partners/stakeholders including key teams within the council: Revenues, Benefits and Shared Services; Housing; Adult Social Services; Work and Skills; Customer Services and DWP. The working group ensures the project plan is delivered including activity relating to resident and partner communication, support services, internal and staff communications, monitoring of impact and governance arrangements and reporting.

- Assisted Digital Support (ADS) - these services were outsourced to Citizens Advice Manchester. This includes Digital Support Hubs which are hosted in libraries and local community centres. The ADS provides support with new online claims for UC and ensures that the claimant has the digital skills to maintain their claim on the digital portal. There is in-house support via the Council's Customer Services Centre but the uptake is low.

- $\quad$ Personal Budgeting Support (PBS) - this service was outsourced to Shelter. They provide telephone and face to face support with Shelter advisers and solicitors. PBS helps claimants to manage their monthly benefits and makes referrals to other agencies where appropriate.

- DWP Partnership Manager - is leading on engagement with partners and has met with a range of services. The specialist UC lead from the Work and Skills team in the council works closely with the DWP Partnership Manager to support this work. For example, they attend events together which and provides a good way to answer queries from the policy/local landscape; making links with private rented landlords through the Neighbourhood Teams; and sharing information on local voluntary and charitable sector (VCS) groups to maximise the chance of those affected having the information regarding the changes and how to access support available.

- $\quad$ DWP is working closely with Registered Housing Providers to verify rent costs to process UC claims and making applications for Alternative Payment Arrangements (APA) for tenants. This is not possible with Private Rented Sector landlords and these claimants are required to obtain evidence of their tenancy and rent costs themselves. DWP must have the consent of the customer to discuss any APA with the landlord. PRS tenants may therefore benefit from a greater awareness of how to obtain an APA. 
- Communications Activity - the local support offer helps residents obtain photo ID, a bank account and an email account. A full mapping of digital access points across the city has been completed. The Communications Team has developed a printed leaflet for residents with information on digital access points, the Personal Budgeting Support and Assisted Digital Support services. This is being sent to partners and organisations across the city. The Council's UC web pages have been updated and a full communications and social media plan is underway. Communication activities are being developed for internal staff who may be affected themselves. DWP are carrying out further engagement activity with employers who need to be aware of the implications of UC roll out for their staff.

- Toolkit of information resources/communications:

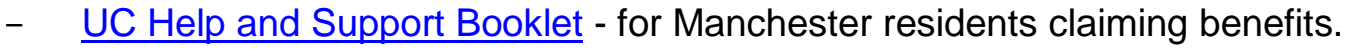

- $\quad$ UC Briefing note - at the strategic level - for partners.

- $\quad$ UC Flow chart - for council staff and partners to aid referrals e.g. where to go for digital support or personal budget support.

- Circulars to schools - these are aimed at staff and the families of pupils.

- $\quad$ UC homepage on the Council website is regularly update and contains the following helpful sections and links to application forms: Universal Credit - for residents to find information

- Information for Staff and Partners - the Work and Skills team have produced a one page UC flowchart (see above) to support staff in giving accurate and simple direction to anyone claiming or needing to claim UC. DWP briefing sessions have been undertaken with the Council's frontline services who are likely to be engaging with residents affected. This includes the Customer Service Centre, Homelessness Team and the Library service. Further services will be identified via the UC Working Group. Council employees have been informed about UC by means of broadcasts and newsletters. E-learning is being explored as a way of making this process coordinated and streamlined.

- Benefit Cap - unlike with Housing Benefit claimants, the Council does not receive notifications of UC claimants subject to the Benefit Cap and therefore the Council cannot carry out any proactive engagement with this group.

\subsection{Summary}

There is a great deal of synergy from the emerging picture of claimants' experience of Full Service UC so far, national evidence and recommendations on how to support claimants through the process, and implementation plans for the delivery of local services with UC claimants.

The roll-out of Full Service in local areas takes time to embed into local systems and support services. It results in a great deal of organisational and operational change for claimants and service providers. Learning from good practice in other areas that are already undergoing the process should be beneficial in the development of local services.

Local service providers have a long journey from when Full Service UC goes live in an area and full implementation for all working age claimants. New claimants or those with a change in circumstances are affected first. Current plans for the managed migration of existing claimants of legacy benefits are yet to be confirmed and the process will not be complete until 2023. It should also be remembered that 
Full Service UC is being rolled out on a test and learn basis and so plans for implementation are subject to change over time. It is therefore important that effective communication occurs to keep staff and claimants engaging with Full Service up to date with the latest advice, documentation and service provision. 


\author{
CRESR \\ Sheffield Hallam University \\ City Campus \\ Sheffield S1 1WB \\ +44 (0) 1142253073 \\ e: cresr@shu.ac.uk \\ w: shu.ac.uk/cresr
}

DOI: $10.7190 /$ cresr.2018.7738236449

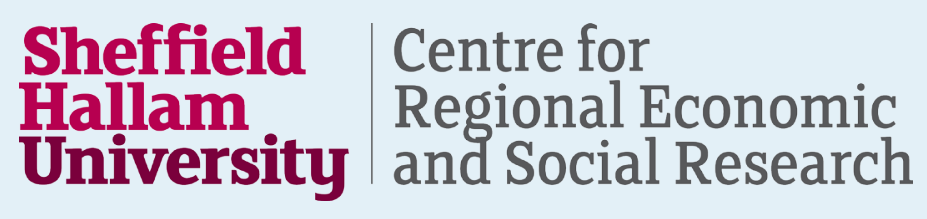




\section{Sheffield Hallam University}

Universal Credit in Rotherham: a transition to full service

BEATTY, Christina <http://orcid.org/0000-0003-0943-9979> and POVEY, Larissa

Available from the Sheffield Hallam University Research Archive (SHURA) at:

http://shura.shu.ac.uk/22800/

\section{Copyright and re-use policy}

Please visit http://shura.shu.ac.uk/22800/ and http://shura.shu.ac.uk/information.html for further details about copyright and re-use permissions. 